\title{
Apresentação Literatura Infantil e Diferenças
}

\author{
Edgar Roberto Kirchof' \\ Iara Tatiana Bonin' \\ Rosa Maria Hessel Silveira"
}

'Universidade Luterana do Brasil (ULBRA), Canoas/RS - Brasil

"Universidade Federal do Rio Grande do Sul (UFRGS), Porto Alegre/RS - Brasil

No Brasil, desde meados da década de 1990, mas especialmente nos anos 2000, o crescimento do interesse por temas ligados às diferenças tornou-se perceptível no panorama social mais amplo, com reflexos também em uma gama considerável de produções endereçadas às crianças. Dentre essas, a literatura infantil apareceu como campo fértil para a tematização de diferenças étnicas, etárias, raciais, de deficiência, de orientação sexual, de gênero, de conformação corporal, dada a quase consensual concepção - entre os educadores - de que a abordagem de temas por meio de produtos culturais de entretenimento, como livros de literatura infantil, filmes, desenhos animados, jogos é sempre produtiva e fecunda. E é no entrecruzamento dessas duas vertentes - a abordagem das diferenças e a literatura voltada para as crianças - que se situa a presente seção temática.

Muitos são os fatores que colaboraram e colaboram para conferir centralidade à temática das diferenças na atualidade, dentre os quais se destacam, por um lado, as iniciativas de movimentos políticos e de uma gama de novos atores sociais que reivindicam direitos específicos - muitos deles incorporados à legislação a partir da premissa constitucional da igualdade e, simultaneamente, do respeito às diferenças culturais, religiosas, étnicas, geracionais etc. Por outro lado, é necessário considerar, para além dos fatores sociais e políticos do Estado brasileiro, os processos de globalização em curso, que tornam cada vez mais porosas as fronteiras que delimitam um dentro e um fora, que definem quem é próximo ou distante, quem somos nós e quem são os outros, e alteram significativamente os panoramas culturais, as rotinas e as práticas dos sujeitos destes tempos.

Conforme Hall (1997), no atual contexto mundial de migrações, resultante do surgimento de novas ordens políticas e econômicas globais, as diferenças tornam-se mais expressivas e se evidenciam pela intensificação de contatos entre diferentes. A produção sem precedentes

Educação \& Realidade, Porto Alegre, v. 38, n. 4, p. 1045-1052, out./dez. 2013. 1045 Disponível em: <http://www.ufrgs.br/edu_realidade> 
de riquezas e de consumo gerada pela globalização produz o deslocamento de enormes contingentes humanos, num mundo de fronteiras tênues, no qual são dinamizadas múltiplas maneiras de ser e de pensar. Contudo, colocados forçosamente em trânsito, muitos desses sujeitos são tidos como diferentes, excluídos, inoportunos, improdutivos, desordeiros. Pode-se dizer que, num contexto de visibilidade das diferenças, não apenas as marcas de nacionalidade, etnia e raça se sobressaem, como também as marcas da suposta anormalidade - corpos outros, tidos como incompletos, desviantes, feios, deficientes também entram em cena e se tornam temas estratégicos na direção de promover atitudes tolerantes na escola e fora dela.

No caso brasileiro, há que se considerar ainda o incremento de ações e políticas governamentais de inclusão social, fato que também impulsiona e dinamiza a temática das diferenças no contexto escolar, promovendo, entre outras consequências, uma mudança em dispositivos legais do campo da educação; pode-se citar, como exemplo, as Leis 10639/2003 e 11.645/2008, que incluem no currículo oficial da rede de ensino a obrigatoriedade da temática História e Cultura Afro-Brasileira e Indígena, ou as leis que estabelecem cotas relativas à etnia, raça ou condição corporal em concursos públicos e para acesso à Universidade.

Do ponto de vista teórico, a abordagem das diferenças assume perspectivas variadas que vão desde a celebração de um pluralismo visto como natural ao social e ao humano - e que muitas vezes se sintetiza na expressão atenção à diversidade - até a crítica radical às formas como se marcam e se classificam os sujeitos em categorias sociais ordenadas de modo hierárquico. Vale ressaltar que, quando matizada por um viés celebratório, a abordagem das diferenças acaba por ressaltar, como tendência geral, o exotismo de certos grupos sociais. A marcação da diferença corre o risco de atuar, então, como traço constitutivo, essencial e imutável.

Tomando por base os escritos de Hall (2008) e de Woodward (2008), entre outros, entendemos que as diferenças não são marcas essenciais nem naturais dos sujeitos e, sim, efeitos de certas formas de representar a materialidade, de $v \hat{e}$-la e de subordiná-la a determinadas maneiras de ordenar e produzir hierarquias sociais. Neste sentido, identidades e diferenças são produções da linguagem e da representação. São contingentes, ou seja, resultam da intersecção entre diferentes componentes, mas também são interdependentes, uma vez que a definição de uma identidade depende fundamentalmente da marcação da sua diferença em relação àquilo a que ela se opõe em determinado sistema classificatório. Ressalte-se que não se trata apenas de dividir o mundo em categorias descritivas assépticas e, sim, de compreender como a linguagem classifica, diferencia, estabelece critérios, define perfis desejáveis - trata-se de um exercício de poder no qual se define quem pertence e quem não pertence a dada categoria, quem é considerado normal ou desvian-

1046 Educação \& Realidade, Porto Alegre, v. 38, n. 4, p. 1045-1052, out./dez. 2013. Disponível em: <http://www.ufrgs.br/edu_realidade> 
te, quem é o sujeito a ser corrigido, confinado, ignorado ou excluído de certas atividades, círculos e privilégios.

Assim como nos demais âmbitos da cultura, no contexto da literatura infantil, a temática das diferenças tem adquirido uma grande relevância nas duas últimas décadas, como inicialmente mencionamos, avolumando-se ano a ano o acervo de livros que exploram, em suas narrativas, diferenças étnicas, etárias, raciais, sexuais, de gênero, de conformação corporal, entre vários outros. É possível perceber, inclusive, a constituição de nichos literários específicos que contemplam algumas diferenças, através da adjetivação do próprio substantivo literatura, como é o caso da literatura indígena, a literatura negra, a literatura surda, por exemplo. Assim sendo, se, até pouco tempo atrás, muitas dessas diferenças eram caracterizadas, nos textos infantis, de forma estereotipada, sem que isso tivesse maior repercussão na comunidade de leitores (e não discutiremos aqui em profundidade a motivação desse conformismo), a partir da influência das perspectivas multiculturalistas e, também, das políticas de inclusão, vem ocorrendo, nas últimas décadas, uma nítida transformação quanto ao modo de representar personagens diferentes em obras infantis endereçadas ao público brasileiro.

Relembre-se, nesse sentido, que, desde o seu surgimento a partir do século XVIII, na Europa, a literatura infantil esteve vinculada a diferentes imagens e representações da infância, determinadas por contextos sociais e históricos específicos. Devido ao seu forte vínculo com a família burguesa e com a escola, ainda no século XVIII, segundo Shavit (2003, p. 26), predominaram duas principais representações do infantil: o entendimento da infância como um repositório de ingenuidade, inocência, candura e graça, como fonte de divertimento e alegria para os adultos, de um lado, e a noção segundo a qual as crianças deveriam ser primordialmente educadas e disciplinadas, de outro. Como se percebe, a primeira concepção está mais ligada aos valores da família burguesa, ao passo que a segunda vincula-se mais fortemente ao intuito pedagogizante e moralizante do espaço escolar.

Assim sendo, não surpreende o fato de que a maior parte dos livros dedicados a crianças, desde o século XVIII até o século XIX, tenha sido marcada por um forte caráter didático e pedagógico, destinado à promoção de valores morais, sendo que a maioria desses textos, principalmente no século XVIII, foi produzida por pedagogos e professores. Observe-se que foi apenas a partir da década de 1970 que a crítica literária, em função do interesse sempre crescente pela literatura endereçada a crianças e jovens, passou a discutir (e questionar) o estreito vínculo entre a pedagogia e esse segmento literário, apontando o risco que tal compromisso traria ao valor estético das obras. Cademartori (2009), ao abordar a questão, adverte-nos de que, se, em décadas mais recentes, “[...] foi repelido o pedagogismo à moda antiga, bem menos fácil é conseguir escapar das nossas idealizações do que seja infância, assim como do viés do que se passou a chamar de 'politicamente correto'” (p. 48).

Educação \& Realidade, Porto Alegre, v. 38, n. 4, p. 1045-1052, out./dez. 2013.1047 Disponível em: <http://www.ufrgs.br/edu_realidade> 
Apresentação da Seção Temática - Literatura Infantil e Diferenças

No trato das diferenças, o viés "politicamente correto" invadiu grande parte dos livros para crianças, sobretudo nos últimos anos, sendo as narrativas literárias tomadas como veículos para a circulação de informações, para o estabelecimento de regras morais e de receituários de como agir em relação a esta ou aquela diferença. Assim, a inserção de assuntos e temáticas que integram o currículo escolar ou que interessam à formação pretendida pela escola parece ser uma das renovadas formas pelas quais se concretiza a aliança entre a literatura para crianças e a pedagogia, na atualidade.

Seguindo, de certa forma, essa tradição pedagógica, a popularização de concepções multiculturalistas dos últimos anos - segundo as quais as diferenças devem ser toleradas, respeitadas, incluídas ou, inclusive, celebradas -, fez com que muitos críticos e intelectuais passassem a se dedicar à desconstrução bem como à crítica de representações estereotipadas (quando não claramente discriminatórias) de minorias em livros para crianças. Essa tendência tem sido bastante forte desde os anos 1970, principalmente no contexto britânico e norte-americano, gerando mudanças significativas nas políticas de produção e circulação de narrativas infantis em diferentes países, incluindo-se o Brasil. Como exemplo, pode-se relembrar que, já no final do século XX, Pinsent (1997) publicava uma obra em que analisava as políticas de igualdade na literatura para crianças, detendo-se na análise de preconceitos de gênero, etnia, idade, deficiência, presentes em alguns desses livros. No Brasil, constituíram-se, nos últimos anos, importantes núcleos de pesquisa sobre literatura infantil que colocam em discussão a temática das diferenças, sendo que alguns pesquisadores destes grupos integram a presente proposta.

Do ponto de vista institucional, vale recordar a consolidação de vigorosas políticas de constituição de acervos de livros de literatura infantil para escolas públicas de todo o país, que se articulam a ações de avaliação de livros inscritos por editoras; em tais avaliações, a inserção das mais variadas expressões das diferenças e o abandono das antigas estereotipias e preconceitos são considerados como critérios, como se pode exemplificar pelo maior programa de todos, em nível federal, que é o PNBE (Programa Nacional Biblioteca da Escola). Tais ações, que são replicadas nos âmbitos estaduais, municipais, de redes privadas de ensino promovem (ao menos, em alguma medida) a incorporação produtiva das diferenças nas novas formas de mercantilização e de consumo da experiência e da vida.

Pois bem: considerando-se a produtividade da temática e a importância do artefato cultural que colocamos em análise - os livros para crianças, o objetivo do presente dossiê é o de colocar em discussão e circulação, para pesquisadores e professores do campo educacional, uma análise de alguns dos fecundos resultados advindos do entrecruzamento entre literatura infantil e diferenças, destacando-se, nos artigos selecionados, diferentes aspectos implicados nesta articulação.

1048 Educação \& Realidade, Porto Alegre, v. 38, n. 4, p. 1045-1052, out./dez. 2013. Disponível em: <http://www.ufrgs.br/edu_realidade> 
Dessa forma, reunimos nele nove textos que abordam a questão da diferença na literatura para crianças e que, a partir desse eixo central, se caracterizam pela multiplicidade de enfoques e temáticas.

O dossiê se inicia pelo texto A Representação da Deficiência em Livros Infantis: séculos XIX e XX, de Ann Dowker, em que a autora focaliza uma das diferenças que tem sido objeto frequente da literatura infantil contemporânea - a deficiência. Sua abordagem traz a novidade da visão histórica de como personagens deficientes atuavam e eram representados já em livros para crianças ocidentais desde o século XIX e início do século XX. A autora observa como, então, a aceitação de uma saúde frágil e da deficiência, dentre outras adversidades, frequentemente era vista como parte da aprendizagem em aceitar a vontade de Deus com relação a todos os aspectos da vida, como autêntica fonte de disciplina espiritual. Entretanto, a complexidade da abordagem da deficiência nos livros da época é maior do que essa simples constatação pode sugerir e tal complexidade é explorada no artigo.

Debruçando-se sobre outra diferença - esta, abordada de modo mais rarefeito na produção literária infantil - Edgar Roberto Kirchof e Iara Tatiana Bonin, nos trazem o artigo intitulado Representações do Feio na Literatura Infantil Contemporânea, em que apresentam uma discussão sobre a representação do feio em livros infantis alinhados com concepções multiculturalistas sobre a diferença. Sob as lentes teóricas dos Estudos Culturais pós-estruturalistas, os autores analisam oito obras brasileiras escritas entre 2008 e 2010 e mostram como, em produções recentes, as representações do feio vêm sendo deslocadas e realinhadas a uma significação positiva, associada à noção de diversidade.

Outra diferença que mereceu a atenção dos autores que compõem o presente dossiê é a que diz respeito ao fator geracional, observando-se que, neste caso, a diferença desfavorecida é a da velhice. Dois estudos se debruçaram sobre este tema, sendo que, no primeiro, intitulado Avós e Netos na Literatura Infantil: vidas compartilhadas, Célia Regina Delácio Fernandes aborda a representação de personagens velhas na literatura infantil contemporânea, através da análise de dez obras recentes, focalizando a convivência entre personagens avós e netos que, apesar das diferenças etárias, conseguem construir relações igualitárias. A autora investiga em que medida as narrativas selecionadas recuperam as vozes, as histórias e os ensinamentos das personagens idosas, observando se as experiências desses sujeitos são valorizadas. No recorte selecionado, constata-se que há uma apresentação positiva da velhice, na medida em que os autores resgatam a figura do velho como o contador de histórias vivenciadas ou inventadas, e, apresentam essa idade da vida como uma possível fonte de sabedoria para as crianças.

Já a pesquisadora lusa Teresa de Lurdes Frutuoso Mendes, no texto intitulado A Morte dos Avós na Literatura Infantil: análise de três álbuns ilustrados, parte do exame de três obras para crianças cujo tema central é a morte dos avós, observando como os autores das mesmas, através da

Educação \& Realidade, Porto Alegre, v. 38, n. 4, p. 1045-1052, out./dez. 2013. 1049 Disponível em: <http://www.ufrgs.br/edu_realidade> 
Apresentação da Seção Temática - Literatura Infantil e Diferenças

criação de universos efabulatórios e imagéticos de grande qualidade estético-literária, trazem abordagens multifacetadas que disponibilizam à criança leitora o conhecimento de formas de como lidar com a morte e a dor da perda. Nos livros em análise, texto e imagem coexistem e se intersecionam para dar resposta a algumas das inquietações da criança em relação à morte de um ente querido.

A diferença étnica, associada a questões culturais, é tematizada em três artigos, sendo que dois deles, sob diferentes enfoques, tratam da questão da presença negra/afrodescendente nos livros atuais que são oferecidos à criança brasileira.

Eliane Santana Dias Debus, em A Literatura Angolana para Infância, a partir da premissa de que conhecer as literaturas africanas de língua portuguesa possibilita às crianças brasileiras uma relação salutar com outras culturas, busca refletir sobre a inserção de tais literaturas nas obras para a infância produzidas no mercado editorial brasileiro. Para tal, analisa títulos de três escritores angolanos: José Eduardo Agualusa - O Filho do Vento (2006) e Nweti e o Mar: exercícios para sonhar sereias (2012); Ondjaki, Ynari - a menina das cinco tranças (2010) e O Leão e o Coelho Saltitão (2009) e Zetho Cunha Gonçalves - Debaixo do Arco-Íris não passa Ninguém (2006) e A Vassoura do Ar Encantado (2012) - mostrando, entre outros aspectos, como a fonte da tradição oral está presente na produção dos três escritores.

Já Dagoberto Buim Arena e Naiane Rufino Lopes, no texto intitulado PNBE 2010: personagens negros como protagonistas, se detêm na seleção de livros efetuada pelo Programa Nacional de Biblioteca na Escola para o ano de 2010, no segmento anos iniciais do Ensino Fundamental, livros estes que são distribuídos às bibliotecas de todas as escolas públicas do país. Identificam inicialmente a escassez de protagonistas negros em tal acervo e contextualizam esse achado em relação a análises anteriores sobre personagens negros na literatura infantil. Além da análise dos livros, os autores trazem resultados de uma pesquisa realizada através de grupos focais com alunos de segundo e de quinto ano do ensino fundamental de uma escola municipal do interior paulista, a partir da abordagem de alguns desses livros. Percepções, atitudes e sentimentos em relação a identidades negras, provocadas pela leitura e observação dos livros também emergiram em tais encontros e são trazidos e discutidos pelos autores.

Já no artigo A Literatura dos Povos Indígenas e a Formação do Leitor Multicultural, Janice Cristine Thiél aborda algumas características estético-literárias de obras de autoria indígena e propõe pensar como o contato com esta literatura infantil pluriétnica e pluricultural pode promover a formação de leitores competentes para a leitura de diferentes formas narrativas. A autora coloca em discussão a linguagem literária e, no caso das produções dos povos indígenas, sua vinculação com a tradição oral.

1050 Educação \& Realidade, Porto Alegre, v. 38, n. 4, p. 1045-1052, out./dez. 2013 Disponível em: <http://www.ufrgs.br/edu_realidade> 
O artigo seguinte aborda um tópico de difícil abordagem e recente tematização na literatura infantil contemporânea; tal é o caso da questão da orientação sexual - especificamente no que diz respeito a famílias com novas configurações, cuja presença na literatura contemporânea para crianças é analisada por Gládis E. da Silva Kaercher e Rosa Maria Hessel Silveira, em Dois Papais, Duas Mamães: novas famílias na literatura infantil. O estudo analisa como famílias homoparentais são representadas em sete livros infantis publicados depois de 2007 e conclui que a tendência de maior recorrência é a que caracteriza o amor entre homens ou mulheres de forma similar às formas com que as relações heterossexuais são comumente representadas - esboçando o discurso do amor romântico, assim como busca aproximar as imagens das famílias homoparentais às imagens tradicionais de felicidade familiar. Assim: alguns dos temas frequentes são a felicidade familiar e discussões sobre criação de filhos e cuidados de casa. Entretanto, duas obras escapam dessa tendência maior, enfatizando a curiosidade infantil pelo amor e pela sua origem.

Fechando o dossiê, Renata Junqueira de Souza e Denise Davila, em O Uso de Textos Polêmicos em Sala de Aula: formação e prática docente, abordam a questão dos livros de literatura infantil sobre diferença (entendendo a temática como inserida nos chamados temas polêmicos) sob outro prisma: o papel dos professores no trabalho em sala de aula com tais textos e a necessidade de formá-los e instrumentalizá-los para um trabalho crítico com os mesmos. Para tanto efetuam uma revisão da literatura sobre temas polêmicos na literatura infantil, discutem o papel do professor como mediador desta leitura e exemplificam as possibilidades de um trabalho produtivo com tais textos, a partir do livro O ônibus de Rosa, de Fabrizio Silei, que tematiza a segregação racial. Na parte final de seu texto, é explorada uma variedade de atividades para inspirar os docentes a lerem de forma reflexiva e realizarem atividades com textos polêmicos em sala de aula.

Enfim, as reflexões apresentadas nos artigos aqui reunidos compartilham do pressuposto de que é necessário avançar em relação à mera aceitação ou ao mero acolhimento das diferenças; da mesma forma, não é suficiente apenas realizar uma crítica aos processos de dominação e discriminação dos diferentes. Em conjunto, os autores destes textos se propõem a refletir sobre as formas de enunciação bem como sobre os processos de significação a partir dos quais as diferenças se constituem, são posicionadas e marcadas, em especial nos livros que se oferecem às crianças das nossas escolas. Como destaca Canclini (2007), a diferença requer, no plano conceitual, uma articulação entre perspectivas que dão visibilidade aos processos de diferenciação e aquelas que problematizam a desigualdade, derivada do acesso diferencial aos bens e recursos em uma sociedade. De todo modo, são os aspectos constitutivos da cultura e da linguagem que estão em questão, ao se falar da produção das diferenças.

Educação \& Realidade, Porto Alegre, v. 38, n. 4, p. 1045-1052, out./dez. 2013.1051 Disponível em: <http://www.ufrgs.br/edu_realidade> 


\section{Referências}

CADEMARTORI, Lígia. O Professor e a Literatura. Belo Horizonte: Autêntica, 2009.

CANCLINI, Néstor García. Diferentes, Desiguais e Desconectados: mapas da interculturalidade. 2. ed. Rio de Janeiro: Editora UFRJ, 2007.

HALL, Stuart. Quem Precisa da Identidade? In: SILVA, Tomaz Tadeu da (Org.). Identidade e Diferença: a perspectiva dos Estudos Culturais. 2a Ed. Petrópolis, RJ: Vozes, 2008, p. 103-132.

HALL, Stuart. A Centralidade da Cultura: notas sobre as revoluções culturais do nosso tempo. Educação \& Realidade, Porto Alegre, v. 22, n. 2, jul./dez. 1997.

PINSENT, Pat. Children's Literature and the Politics of Equality. London: David Fulton publishers, 1997.

SHAVIT, Zohar. Poética da Literatura para Crianças. Lisboa: Editorial Caminho, 2003.

WOODWARD, Kathryn. Identidade e Diferença: uma introdução teórica e conceitual. In: SILVA, Tomaz Tadeu da (Org.). Identidade e Diferença: a perspectiva dos Estudos Culturais. $8^{\text {a }}$ Ed. Petrópolis, RJ: Vozes, 2008. P. 7-72.

Edgar Roberto Kirchof é graduado em Letras (Português/Alemão) pela UNISINOS e em Teologia pela Escola Superior de Teologia. Mestre em Ciências da Comunicação pela UNISINOS e doutor em Linguística e Letras pela PUC/RS, com Pós-Doutorado Universidade de Kassel, Alemanha. É professor adjunto da Universidade Luterana do Brasil no (PPGEDU) e docente no Curso de Letras.

E-mail: ekirchof@hotmail.com

Iara Tatiana Bonin é graduada em Pedagogia pela Universidade Federal de Santa Catarina. Mestre em Educação pela Universidade de Brasília e doutora em Educação pela Universidade Federal do Rio Grande do Sul. É professora adjunta da Universidade Luterana do Brasil no (PPGEDU) e docente no Curso de Pedagogia. Sua produção vincula-se ao campo dos Estudos Culturais e, em especial, à temática indígena.

E-mail: iara.bonin@uol.com.br

Rosa Maria Hessel Silveira é professora titular aposentada da Faculdade de Educação da UFRGS e professora colaboradora permanente do PPGEdu da UFRGS, na linha "Estudos Culturais em Educação". Orienta trabalhos de mestrado e doutorado e organizou as obras "Estudos Culturais para professor@s” e "Cultura, poder e educação”. É pesquisadora 1C do CNPq e atual coordenadora do NECCSO (Núcleo de Estudos Currículo, Cultura e Sociedade).

E-mail: rosamhs@terra.com.br

1052 Educação \& Realidade, Porto Alegre, v. 38, n. 4, p. 1045-1052, out./dez. 2013. Disponível em: <http://www.ufrgs.br/edu_realidade> 